type of approach to help the engineer design a system to cater for human capabilities may, therefore, be very limited.

JeAN ShaOuL

\section{Biological Electron Spin}

Biological Applications of Electron Spin Resonance. Edited by Harold $\mathbf{M}$. Swartz, James R. Bolton and Donald C. Borg. Pp. $x+569$. (Wiley Interscience: New York and London, September 1972.) $£ 11.55$.

ELECTRON spin resonance spectroscopy was discovered in 1945, and first applied to biology in 1954 . In 1958 Ingram produced the first book on applications of e.s.r. outside physics, and included a short chapter on biological and medical applications. The length of the present book shows that the subject is still growing according to an exponential law. How much has been accomplished in the 18 years since the first publication?

A quick glance through this book shows that e.s.r. is now being applied throughout biology, at the molecular level. It is particularly valuable in the study of photosynthesis; of enzymic reactions, especially those concerned with electron transport; of radiation biology and of various aspects of cancer. In the spin label method, which first appeared in 1965, there is a technique whose possibilities seem to be limited only by the ingenuity of the investigator. On the technical side of e.s.r. there have been great advances. Spectrometers are now reliable and easy to use, and the recent coupling of spectrometers to computers has led to improved spectra and improved analysis of spectra. The present book contains a detailed and valuable chapter on quantitative e.s.r. However, the basic problem remains, that on the one hand cells are complex and on the other hand e.s.r. spectra obtained from them are, in most cases, relatively nonspecific. So the use of e.s.r. has not led to any major advances in biology; nevertheless all biologists who are interested in the molecular aspects of their subject should be aware of the potentialities of the method.

How suitable is the present book as an introduction to e.s.r. for biologists and physicians? The editors, two physicians and a chemist, produced it because of their belief that the full potential of e.s.r. in biology was not being realized, principally because biologists did not have an adequate understanding of this method, and that a principal obstacle was the lack of a good text directed towards biologists. Accordingly the book begins with an explanation of the method, on a three-level approach, excessively simple in the introduction, and as simple as possible in the first three chapters, with more advanced material set off in small type.
Although all biologists and physicians will be able to follow the introduction. I am less sure about the explanatory chapters, where one is rapidly plunged into the mysteries of tensors, axes of symmetry, slow exchange and fast exchange, crystal field splitting etc. Most biologists and physicians, I feel, will heave a sigh of relief when they reach the more familiar ground of "Cells and Tissues" in chapter 4. My advice to them would be to skip the early chapters, to go straight to the applications, which are covered very thoroughly, and then, if they want to use e.s.r., to get the collaboration of a physicist or chemist who understands the technique.

The book is written by ten authors, and suffers inevitably from some lack of cohesion and some variability of standard. However, the treatment never drops below an adequate standard, and I recommend it as essential reading for all biologists approaching e.s.r. for the first time, and an essential acquisition for libraries.

S. J. WYARD

\section{Nemerteans}

Nemerteans. By Ray Gibson. Pp. 224. (Hutchinson: London, August 1972.) $£ 3$ hardback; $£ 1.75$ paperback.

THE nemerteans are an interesting but relatively neglected group and this new book is a timely and welcome addition to the well known Hutchinson University Library Series, Much of the book is a straightforward account of what is known about the structure and biology of nemertines. In this it will prove most useful to students of invertebrates and to marine biologists and also direct attention to subjects of interest which require further study. I would have preferred structure and function to have been associated more closely than they have been. The section on the mechanics of the body wall, body shape, locomotion and hydrostatic skeleton, for example, could with advantage have been included with the descriptions of morphology. Similarly, discussion of what little is known about osmoregulation might well have been included with the account of the excretory organs, the excretory system, excretion and the origin of the freshwater and terrestrial forms which comes elsewhere. In general this divorce of structure and function is what I disliked most about this book, which does contain, nevertheless, a wealth of clearly presented information. The contents of the chapter on general physiology and many of the facts presented in the chapter on ecology should, in my view, have been included with the descriptions of structure. Although the rise in the quality of production in this series has been accompanied by a concomitant rise in price, how much better this new volume is in appearance as compared with the earliest issues in the series. Dr Gibson's drawings are excellent. There is a plate showing ultrastructural details and a colour plate illustrating Geonemertes (taken by $\mathrm{Dr}$ Batham) and the vascular system of Malacobdella visualized by the useful exopeptidase method done by the author.

This book will serve a useful purpose in stimulating further work on these interesting animals. R. P. DALES

\section{Dating Man}

Calibration of Hominoid Evolution: Recent Advances in Isotopic and Other Dating Methods Applicable to the Origin of Man. (Proceedings of the Symposium held at Burg Wartenstein, Austria, July 1971.) Edited by W. W. Bishop and J. A. Miller. Assisted by Sonia Cole. Pp. viii +487 . (Scottish Academic Press: Edinburgh; University of Toronto: Toronto, June 1972.) (Distributed in the UK by Chatto and Windus Ltd, published for the Wenner Gren Foundation for Anthropological Research, New York.) $£ 7.60$.

THE conference of which this volume is the product was concerned with recent advances in isotopic and other dating methods and their application to dating the emergence of man. The dating technologists and geologists included Thurber, Broecker and Bender, Bandy, Miller, Fitch, Cox, Dalrymple, Fleischer and Hart, Turekian and Bada, Bishop, Van Couvering, Brown, Curtis and Hay. The palaeontologists and archaeologists were Kurtén, Walker, Cooke and Maglio, Clark Howell, Pilbeam and Isaac. Nineteen chapters are followed by discussions, commentaries and three appendices.

This book is an admirable and very topical source book for all palaeoanthropologists and archaeologists. It contains the latest dates together with new interpretations of the evidence for man's evolution. The papers are all authoritative and the whole publication amounts to an invaluable reference work. One or two well-known names which might have been included are missing, but this hardly detracts from the value of the book. The intepretation of these new dates for man's evolution has very farreaching implications, for reliable dating is an essential basis for any logical interpretation of the fossil evidence. It will be an invaluable reference work for all who are concerned with this rapidlygrowing field of study, and will allow us all to reassess our ideas about man's origin and prehistory with considerably more confidence in the hardening data of Plio-Pleistocene chronology than we have been able to muster in the past.

Bernard Campeell 